\title{
Mechanistic Studies with DNA Polymerases Reveal Complex Outcomes following Bypass of DNA Damage
}

\author{
Robert L. Eoff, ${ }^{1}$ Jeong-Yun Choi, ${ }^{2}$ and F. Peter Guengerich ${ }^{1}$ \\ ${ }^{1}$ Department of Biochemistry and Center in Molecular Toxicology, Vanderbilt University School of Medicine, \\ 638 Robinson Research Building, 2200 Pierce Avenue, Nashville, TN 37232-0146, USA \\ ${ }^{2}$ Department of Pharmacology, School of Medicine, Ewha Womans University, Seoul 158-710, Republic of Korea
}

Correspondence should be addressed to F. Peter Guengerich, f.guengerich@vanderbilt.edu

Received 6 May 2010; Accepted 12 August 2010

Academic Editor: Ashis Basu

Copyright (C) 2010 Robert L. Eoff et al. This is an open access article distributed under the Creative Commons Attribution License, which permits unrestricted use, distribution, and reproduction in any medium, provided the original work is properly cited.

\begin{abstract}
DNA is a chemically reactive molecule that is subject to many different covalent modifications from sources that are both endogenous and exogenous in origin. The inherent instability of DNA is a major obstacle to genomic maintenance and contributes in varying degrees to cellular dysfunction and disease in multi-cellular organisms. Investigations into the chemical and biological aspects of DNA damage have identified multi-tiered and overlapping cellular systems that have evolved as a means of stabilizing the genome. One of these pathways supports DNA replication events by in a sense adopting the mantra that one must "make the best of a bad situation" and tolerating covalent modification to DNA through less accurate copying of the damaged region. Part of this so-called DNA damage tolerance pathway involves the recruitment of specialized DNA polymerases to sites of stalled or collapsed replication forks. These enzymes have unique structural and functional attributes that often allow bypass of adducted template DNA and successful completion of genomic replication. What follows is a selective description of the salient structural features and bypass properties of specialized DNA polymerases with an emphasis on Y-family members.
\end{abstract}

\section{Introduction}

The ability to replicate covalently modified or "damaged" DNA and unusual secondary structures in template DNA (i.e., non-B DNA conformations) is critical to the survival and evolution of all biological systems. Highly accurate B-family DNA polymerases are the primary means of replicating eukaryotic genomes with few mistakes (e.g., error rates of $10^{-4}-10^{-7}$ ), although subsequent mismatch repair activity improves the fidelity of replication about 100 -fold. Covalent modification of nucleic acids can disrupt normal replication processing of the heritable material. Of course, damage to DNA can be recognized and removed from the genome prior to replication but this repair capacity is not perfect and lesions do persist in the genome during S-phase. Damage signals that occur during replication (S-phase) and postreplication (G2/M phase) can activate signaling pathways that ultimately recruit a set of specialized DNA polymerases to the replication fork. These enzymes provide the cell with a means of "tolerating" the modified residue by catalyzing DNA synthesis opposite a number of different lesions, as well as non-B form DNA secondary structures that can inhibit normal replication. The outcome of this specialized DNA synthesis reaction can be accurate and promote cell survival or it can be mutagenic, which often proves deleterious to cellular homeostasis. A precise description of how bypass polymerases from different organisms function to tolerate damage to the genome is a fundamental aspect of understanding mechanisms of mutagenesis. We describe results that have helped define the potential ramifications of certain DNA lesions to the replication machinery.

Life is dependent upon accurate replication or "copying" of DNA by enzymes called DNA polymerases [1-3]. The same chemical reaction is utilized to replicate the genome of all organisms studied to date, namely, nucleophilic attack of a deprotonated $3^{\prime}$-oxygen atom on the primer terminus upon the $\alpha$-phosphate of an incoming dNTP [4]. Related organisms tend to share more similarities in terms of the enzymes and proteins associated with copying DNA, with some features more highly conserved than others. Enzymatic 
redundancy with functional distinction and complex pathway overlap are overarching themes describing how cells tolerate DNA damage $[5,6]$. A careful balance is needed to ensure that mechanisms primarily retained to "protect" the genome do not result in unnecessary mutagenic events and/or cell death.

Numerous types of chemical modifications to DNA have been identified (Figure 1) and many agents that are known to damage DNA are also carcinogens $[8,9]$. Biochemical analysis of DNA polymerase activity has shown that these enzymes utilize a series of molecular checkpoints that typically promote formation of "Watson-Crick" base pairing geometry and, therefore, stable propagation of DNA [10]. One can easily imagine that changing the chemical structure of DNA will alter the catalytic properties of DNA polymerases. Some DNA polymerases show less tolerance to covalent modification of DNA, including the B-family DNA polymerases such as, pols $\delta$ and $\varepsilon$, both of which possess exonuclease activity. These enzymes are able to bypass certain DNA lesions [11, 12] and this bypass activity probably bears relevance towards what occurs in vivo (Figure 2). When considering translesion DNA synthesis in general, it is believed that nonessential DNA polymerases, such as the Y-family, perform bypass more efficiently than the so-called "high fidelity" exonuclease containing enzymes. The most important questions to ask related to DNA adduct bypass pertain to how the presence of DNA adducts produce changes in nucleotide selectivity (i.e., fidelity) due to altered structural features and/or changes in catalytic rate constants for individual DNA polymerases. Most research on translesion DNA synthesis attempts to focus on DNA modifications that have been correlated with increased mutagenesis and/or the manifestation of disease [13]. Much of the work done during the last decade has focused on understanding how nonessential polymerases, most of which do not possess exonuclease activity, catalyze DNA synthesis opposite damaged DNA [14]. Numerous exemplary efforts from the groups of Woodgate, W. Yang, Friedberg, Lehmann, Loeb, Geacintov, Levneh, Nohmi, Walker, Goodman, the Prakashs, Burgers, Lloyd, and Kunkel and our long-time collaborators at Vanderbilt-M. Egli, C. J. Rizzo, L. J. Marnett, T. M. Harris, and M. P. Stone-to name a few individuals have increased our understanding of translesion DNA synthesis in tremendous ways. Of the nonessential pols studied to date, the Y-family DNA polymerases seem to be the primary means of tolerating genotoxic insults through direct bypass of adducts during S-phase and the G2/M phase transition, although the B-family members pol II and pol $\xi$ also play important roles in prokaryotic and eukaryotic cells, respectively. While the activity of nonessential or "specialized" DNA polymerases can suppress damage-induced mutagenesis [15], this suppression at sites of damage can still lead to nontargeted mutations elsewhere [16]. Indeed, the misregulation of their activity is believed to participate in mutagenic events and antagonistic pleiotropy associated with tumorigenesis and aging because they do not possess exonuclease "proofreading" ability and they are generally more likely to make mistakes on undamaged template DNA (Figure 2) [17-24]. These specialized DNA polymerases generally share the following attributes: (i) they possess no intrinsic exonuclease activity (except for pol II), (ii) they have spacious active sites with fewer structural and kinetic checks upon the nascent base pair, (iii) they exhibit reduced processivity, (iv) the error rates with unmodified template DNA are higher than for replicative counterparts, and (v) there are damage-inducible signaling pathways that recruit them to replication foci. Structurally speaking, the overall domain architecture of Y-family DNA polymerases is similar to that of other polymerases, including B-family members (Figure 2). However, there are several important differences that are obvious from the crystal structures. For example, the active site of Y-family DNA polymerases is much larger and more exposed to solvent than B-family counterparts. The Y-family also possesses the unique "little finger" domain, as well as N-terminal extensions such as the N-digit of REV1 and the N-clasp of human pol $\kappa$ [14]. Some elements of so-called translesion or specialized DNA synthesis events are relatively clear now. For example, the genetic, biological, and biochemical data supporting the preeminent importance of human pol $\eta$ in the largely accurate bypass of UV-induced cyclobutane pyrimidine dimers (CPDs) is very strong [25-28]. Still, there remain many outstanding questions of interest related to mechanisms that promote DNA damage tolerance. Following is a summary of the literature concerning how these specialized DNA polymerases perform synthesis across DNA adducts.

\section{Bypass of Abasic Sites and Small Oxidative Lesions}

Perhaps the most prevalent form of genetic insult in cells is loss of a purine/pyrimidine base to generate an abasic site (Figure 1(a)) [29, 30]. Generation of abasic sites can occur enzymatically through the action of glycosylases, from spontaneous hydrolysis at the glycosidic bond or from reactions with exogenous chemical agents $[31,32]$. Abasic sites provide no purinic or pyrimidinic moiety for DNA polymerases to use as a template during replication. Naturally occurring deoxyribose abasic sites exist in equilibrium between the ring-closed $\alpha$ - and $\beta$-hemiacetals (99\%) and ring-opened aldehyde or hydrated aldehyde $(<1 \%)$, which has led to the common practice of studying a stable tetrahydrofuran (THF) moiety instead of a true abasic site. Mechanistic studies with the THF analogue (of natural abasic sites) highlight the concept that if the enzyme does not encounter a base then the normal catalytic pathway is diverted into a chemical path that generally results in the incorporation of dATP opposite the THF abasic site (i.e., the "A-rule") [33]. In Escherichia coli cells, pol $\mathrm{V}$ appears to provide the most efficient means of bypassing abasic THF sites, with insertion of dATP being the preferred catalytic event [34]. In contrast to events in E. coli, eukaryotic cells appear to rely upon a combination of DNA polymerases to bypass abasic moieties. DNA polymerases $\delta$ and REV1, in combination with pol $\xi$, bypass abasic sites in vitro and in vivo $[35,36]$. Recently, yeast pol $\varepsilon$ was reported to bypass abasic sites in vitro [37]. Dpo4 inserts dATP opposite the THF moiety 


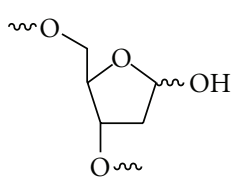

Abasic site<smiles>COCC1OCCC1OC</smiles>

THF

abasic site

analogue<smiles>Cn1c(=O)[nH]c2c(=O)[nH]c(N)nc21</smiles>

8-oxodG

(a)

$\mathrm{R}_{1}$

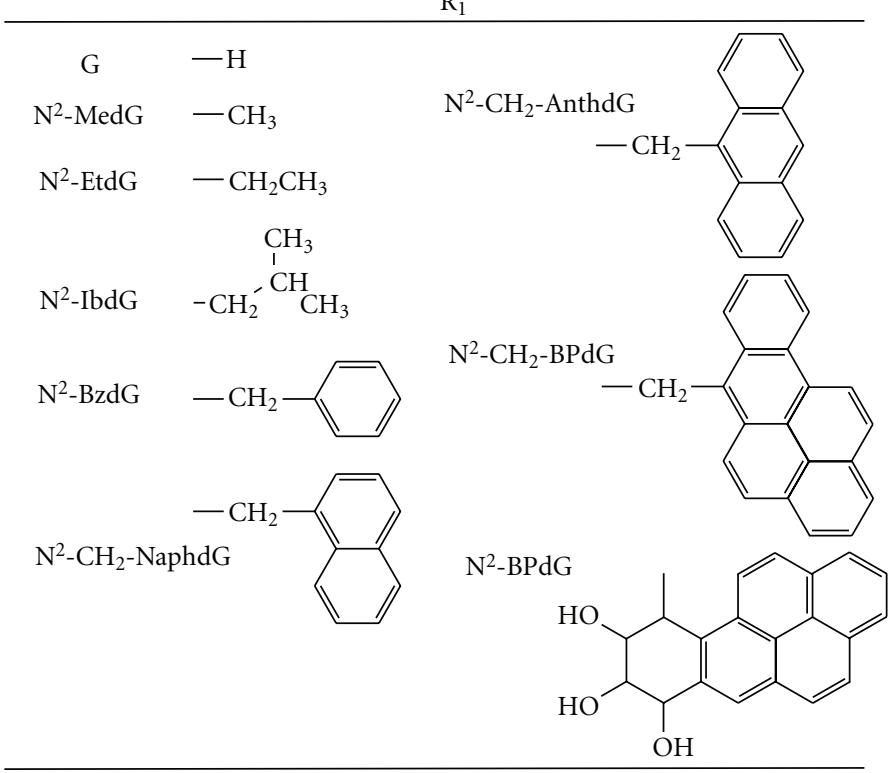

(b)

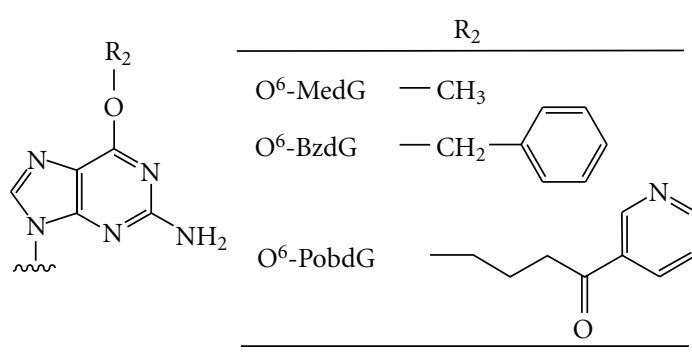

(c)<smiles>[R3]Nc1ncnc2c1ncn2C</smiles><smiles>Cn1cnc2c(=O)n3cccnc3nc21</smiles>

$\mathrm{M}_{1} \mathrm{dG}$

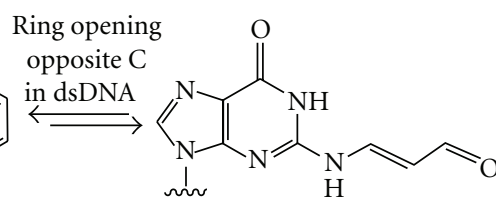

$\mathrm{N}^{2}-\mathrm{OPdG}$<smiles>Cn1cnc2c(=O)n3cc[nH]c3nc21</smiles>

$1, \mathrm{~N}^{2}-\varepsilon-\mathrm{dG}$

(d)

FIGURE 1: Overview of DNA adducts. The number of DNA adducts formed through interactions with reactive chemicals or ionizing radiation is vast, and more thorough reviews have been performed elsewhere [7]. We have chosen to focus on some of the most thoroughly studied DNA adducts, in terms of how the adduct affects DNA polymerase structure and function. A, abasic sites and 8-oxodG; B, minor groove $\mathrm{N}^{2}$-dG adducts; $\mathrm{C}$, major groove $\mathrm{O}^{6}-\mathrm{dG}$ and $\mathrm{N}^{6}$-dA adducts; $\mathrm{D}$, exocyclic dG adducts. Adduct stereospecificity is not shown in structures of of $\mathrm{B}[a] \mathrm{P}$ DNA adducts. 


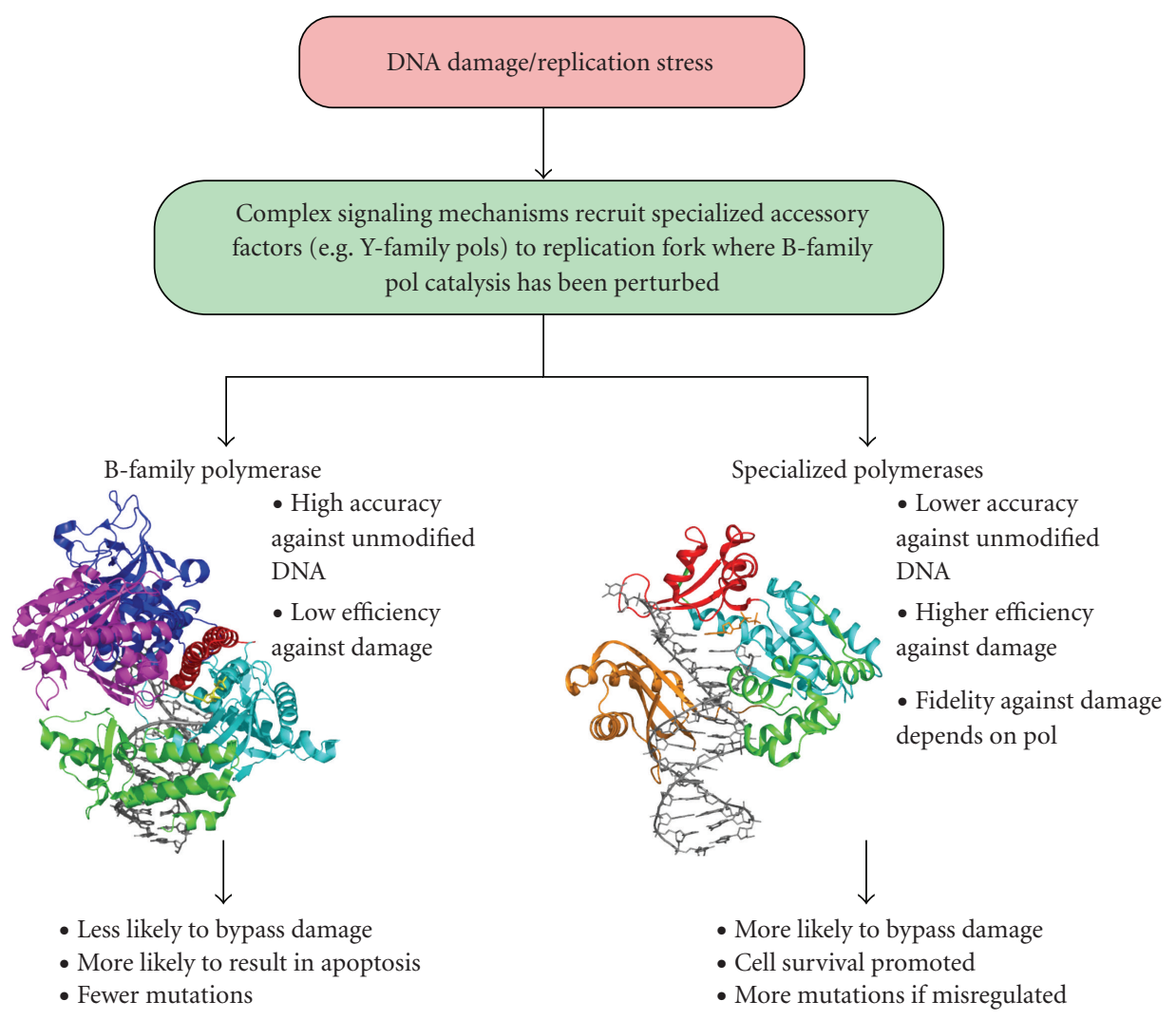

FIGURE 2: Schematic overview of DNA damage tolerance and two families of DNA polymerases that are partitioned at the replication fork during translesion DNA synthesis. Genotoxic insults can lead to damage that stalls or slows the replication fork. Signaling through the ATM and ATR kinases leads to the recruitment of nonessential "bypass" polymerases. The Y-family pols appear to be the primary means of synthesizing past DNA lesions at stalled or collapsed replication forks but misregulation of these enzymes can lead to events that promote mutagenesis and ultimately tumorigenesis. The exquisite regulation of Y-family DNA polymerases is vital to cellular survival in the face of DNA damage and in the prevention excessive mutagenesis. Two DNA polymerase structures are shown, that of the catalytic subunit of the B-family member yeast pol $\delta$ in ternary complex with 12/16-mer DNA (gray) and an incoming dCTP (yellow) (pdb id code 3IAY; [42]). The Y-family polymerase Dpo4 from S. solfataricus is also shown in ternary complex with 13/18-mer DNA (gray) and an incoming ddATP (pdb id code 1JX4; [43]). Both enzymes possess the core the palm (cyan), finger (red), and thumb (green) domains. Pol $\delta$ also has a $3^{\prime}$ to $5^{\prime}$ exonuclease domain (magenta), as well as the N-terminal domain (dark blue). The little finger domain (orange) is unique to the Y-family.

with $\sim 100$-fold reduction in catalytic efficiency [38]. Both human and yeast pol $\eta$ preferentially insert dGTP opposite THF with a large $\left(\sim 10^{3}\right)$ decrease in efficiency, but the preference for dGTP is only very small for human $\eta$, as dATP insertion opposite THF is about the same as dGTP [39]. Human pol $\kappa$ catalytic efficiency decreases $\sim 10^{4}$ when attempting to insert opposite THF, although the addition of accessory factors such as PCNA, RFC, and RPA increases the efficiency $\sim 40$-fold [40]. Human pol $\iota$ inserts either dGTP or dTTP opposite THF with $\sim 10$-fold reduction in efficiency [41].

One issue with the THF studies is that bypass of natural abasic sites involves primarily accurate bypass (the "C-rule"), which appears to depend on the action of REV1 (Figure 3) [44]. Because depurination is much more frequent than depyrimidination and guanine is the base more likely to depurinate (generating an abasic site), there is an intellectual attraction to the concept that an enzyme that primarily inserts dCTP (regardless of the template base identity) would be involved in bypass of abasic sites. This model highlights the role of the deoxycytidyl transferase activity of REV1 in "accurate" bypass of abasic sites. REV1 catalyzes phosphoryl transfer in a protein template-dependent manner by using an arginine residue to pair with dCTP [45]. Consequently, the REV1 enzyme primarily (but not exclusively) catalyzes incorporation of dCTP, regardless of the identity of the template sequence.

Cells are constantly exposed to exogenous and endogenous sources of oxidative damage to DNA [31, 46, 47]. Guanine is the most readily oxidized base in the genome and 7,8dihydro-8-oxo-2'-deoxyguanosine (8-oxodG) (Figure 1(a)) has long been considered a classical marker of oxidative damage to the genetic code [48]. The 8-oxodG adduct is strongly mutagenic in bacterial and eukaryotic cells, inducing primarily $\mathrm{G}$ to $\mathrm{T}$ transversions [49]. At least four pathways prevent 8-oxodG adducts or 8-oxodG:A mispairs from accumulating in the eukaryotic genome [50-54]. In vitro analysis of DNA and RNA polymerase activity opposite 


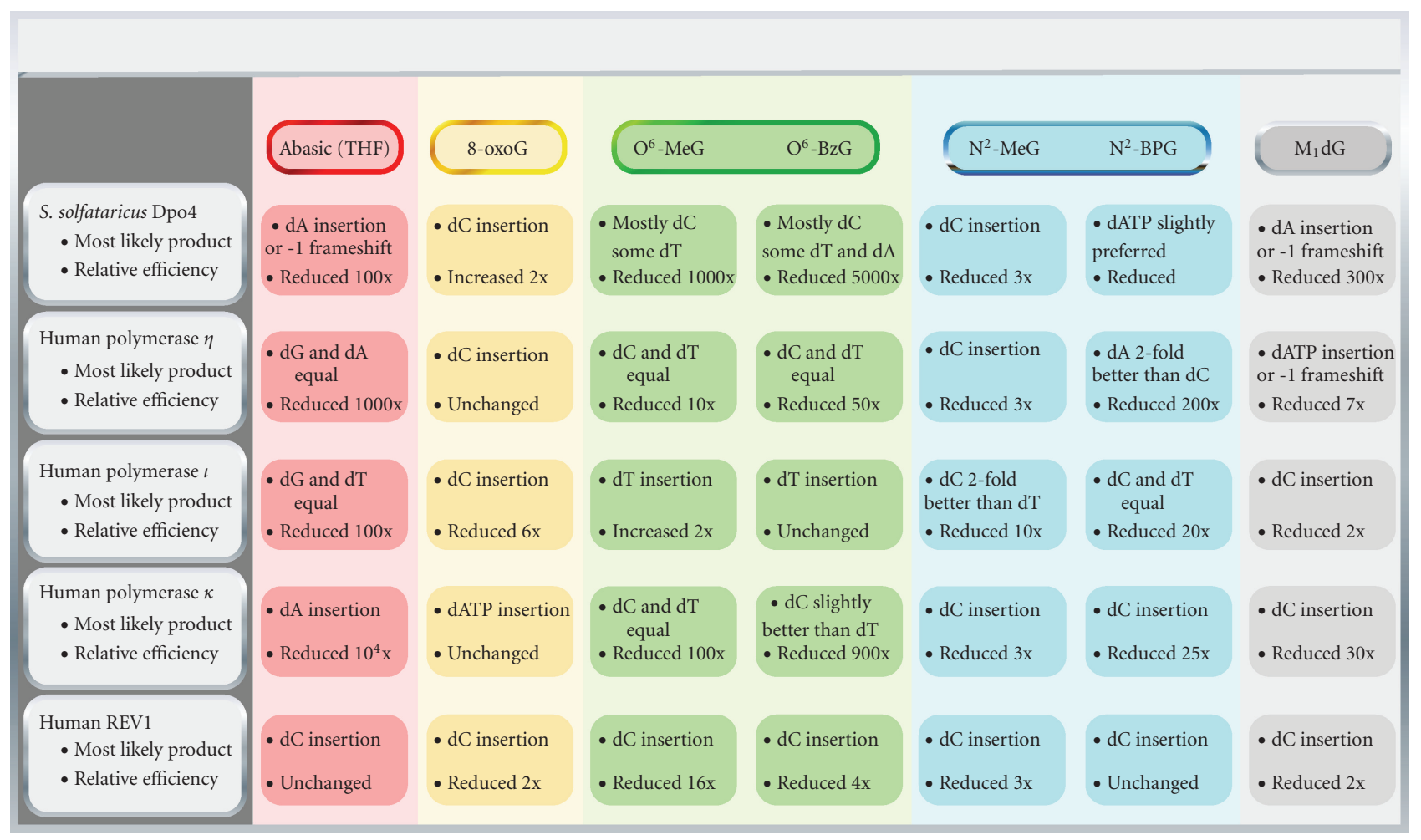

FIGURE 3: Summary of DNA adduct bypass capabilities for selected DNA polymerases. The table attempts to summarize the effect of different DNA adducts on Y-family DNA polymerase catalytic efficiency and makes note of the most likely dNTP insertion event for each lesion. Please see the main text for the corresponding references.

the lesion has provided some insight into mechanisms of 8 -oxodG bypass. In general, most DNA polymerases tested show either a preference for incorrect insertion of dATP or are kinetically indifferent to dCTP or dATP [55-60]. Some notable exceptions to this rule have been documented: (i) Saccharomyces cerevisiae DNA polymerase $\eta$ [61-63] and (ii) Dpo4, the $\operatorname{din} B$ homologue from the crenarchaeote Sulfolobus solfataricus [64-66]. These enzymes are at least 20 -fold more efficient at accurate bypass of 8 -oxodG than incorrect insertion of dATP (Figure 3). It is also notable that the fidelity of 8 -oxodG bypass by human pols $\lambda$ and $\eta$ is increased (100-fold and 27-fold, resp.) by the inclusion of the accessory factors PCNA and RPA [63]. Both human pol $\iota$ and REV1 perform relatively accurate bypass of 8-oxodG by preferentially inserting dCTP with only moderate loss of efficiency $[67,68]$.

The apparent functional superiority of Dpo4 and pol $\eta$ at maintaining genomic integrity during bypass of 8 -oxodG is at least partly due to an electrostatic contact between the little finger domain and the $\mathrm{O} 8$ atom of 8-oxodG [64]. Crystal structures with Dpo4 in complex with 8-oxodG modified DNA template reveal that Arg-332 forms a hydrogen bond with the O8 atom of 8-oxodG, which apparently stabilizes the normal anti conformation around the glycosidic bond and presents the unperturbed Watson-Crick face of the base to the incoming dNTP. Super-imposition of yeast pol $\eta$ with Dpo4 suggests that Lys-498 may provide a similar function to Arg-332. At the nucleoside level, 8-oxoG preferentially adopts the syn orientation that will present the Hoogsteen edge of the base to the incoming dNTP in the active site of polymerases [69]. The syn 8-oxodG:dA pairing mode has been observed for many polymerases, including Dpo4 $[55,66]$. However, stabilization of the anti mode for 8oxodG by Dpo4 results in an energy of activation value that is actually lower for Dpo4-catalyzed insertion of dCTP opposite 8-oxodG than dCTP insertion opposite dG, thereby favoring accurate bypass [66].

In contrast to Dpo4, the human DinB homologue pol $\kappa$ is quite error-prone at bypass of 8 -oxoG, preferentially inserting dATP opposite the lesions [70]. There are at least three distinct molecular features that distinguish the activities of Dpo4 and pol $\kappa$ during insertion opposite 8 -oxodG [70]. The first distinction can be found in the little finger residue Arg-332 that stabilizes anti 8-oxodG in Dpo4. In pol $\kappa$ the analogous residue is Leu-508, which obviously cannot mediate electrostatic stabilization of anti 8-oxodG. Mutating Leu-508 to lysine shifts the kinetic preference towards accurate insertion of dCTP opposite 8oxodG. The second distinction resides in the fact that the active site of pol $\kappa$ is sterically more constrained than Dpo4, especially in considering the residues that form the "roof" over the nascent base pair. Residues Phe-155, Ser-134, Pro153, Met-135, and Ala-151 from the finger domain of pol $\kappa$ correspond to Val-62, Gly-41, Pro-60, Ala-42, and Gly58 in Dpo4. The active site of pol $\kappa$ only accommodates a single template residue. The third distinction between 
pol $\kappa$ and Dpo4-catalyzed bypass of 8 -oxodG is inferred from kinetic and structural differences between these two enzymes. The most striking structural difference between pol $\kappa$ and Dpo4 is the N-terminal extension called the "Nclasp" in pol $\kappa$ that is vital to polymerase activity. Dpo4 has no analogous domain. The N-clasp sits a top the DNA binding cleft, encircling the DNA, and serves to stabilize the position of the little finger domain relative to the polymerase core domains. The contacts made between the $\mathrm{N}$-clasp, the finger, and little finger domains are presumably limiting conformational fluctuations near the template DNA binding region. Thus, the more thermodynamically stable syn orientation of 8-oxoG will therefore be more difficult to shift back to the anti form (i.e., the mode ideal for accurate insertion of $\mathrm{dCTP}$ ) in the pol $\kappa$ active site relative to Dpo4.

\section{Major and Minor Groove DNA Adducts}

The site of adduct formation on heterocyclic purine/pyrimidine residues is an important determinant of whether the lesion will be blocking or whether a given polymerase will perform synthesis in an accurate or inaccurate manner. Most replicative DNA polymerases have contacts with the hydrogen bond accepting atoms of purines and pyrimidines on the minor groove portion of the dsDNA (N3 for purines and $\mathrm{O} 2$ for pyrimidines) near the active site and are consequently strongly impeded by minor groove adducts [71]. Y-family polymerases do not possess an analogous minor groove check upon base pair geometry, which when combined with a more spacious active site results in a greater ability to tolerate bulky minor groove DNA adducts.

The N2 atom of guanine is located on the minor groove side of double-stranded (ds) DNA and is susceptible to modification by $\alpha, \beta$-unsaturated aldehydes such as, acrolein, crotonaldehyde, malondialdehyde, and trans-4-hydroxynonenal, as well as oxidation products of heterocyclic aromatic amines (e.g., $N$-hydroxy-2-amino3-methylimidazo[4,5- $f$ quinoline) and polycyclic aromatic hydrocarbons (e.g., benzo[a]pyrene) [72-75]. The effect of minor groove adduct bulk on the kinetics of Y-family or replicative polymerase catalysis has been studied in a systematic manner by increasing the size of a series of $\mathrm{dG}$ adducts from $\mathrm{N}^{2}$-methyl(Me)dG to $\mathrm{N}^{2}$-methylenyl(6benzo $[a]$ pyrenyl)dG $\left(\mathrm{N}^{2}-\mathrm{BPdG}\right)$ (Figure $1(\mathrm{~b})$ ) [76-80]. Of course, adducts can also form on the major groove [81]. The effect of adduct size on the major groove side was studied for the Y-family and replicative polymerases using $\mathrm{O}^{6}$-(Ar)alkyl$\mathrm{dG}$ adducts ranging in size from $\mathrm{O}^{6}$-methyl- $\mathrm{dG}\left(\mathrm{O}^{6}\right.$-MedG) to $\mathrm{O}^{6}$-pyridyloxobutyl-dG $\left(\mathrm{O}^{6}\right.$-PobdG) (Figure $1(\mathrm{c})$ ) [80, 82].

Kinetic and structural work with the model Y-family DNA polymerase Dpo4 provides an initial framework for understanding bypass of minor groove DNA adducts. Unlike model replicative polymerases (i.e., A- and B-family polymerases from model organisms such as, bacteriophage T7 and RB69), which are severely inhibited by even the small $\mathrm{N}^{2}-\mathrm{MeG}$ adduct, Dpo4 is able to bypass a series of minor groove adducts with negligible inhibitory effects on catalytic efficiency and moderate effects upon fidelity [83]. Two crystal structures of Dpo4 in complex with the bulky $\mathrm{N}^{2}$-methylenyl-(2-naphthyl)-dG $\left(\mathrm{N}^{2}-\mathrm{CH}_{2}-\mathrm{Naph}-\mathrm{dG}\right)$ adducted DNA have been reported [83]. Interestingly, the $\mathrm{N}^{2}-\mathrm{CH}_{2}-\mathrm{Naph}-\mathrm{dG}$ adduct was found to adopt two distinct postinsertion orientations in complexes that should be identical. One structure placed $\mathrm{N}^{2}-\mathrm{CH}_{2}-\mathrm{Naph}-\mathrm{dG}$ in the anti-orientation, which forces the cytosine residue at the primer terminus out of the active site into the growing minor groove face. The second structure revealed $\mathrm{N}^{2}-\mathrm{CH}_{2}-$ Naph-dG rotated into the syn orientation, which allows the $\mathrm{N} 4$ exocyclic amino group of cytosine to form a bifurcated Hoogsteen pair with the N7 and $\mathrm{O} 6$ atoms of $\mathrm{N}^{2}-\mathrm{CH}_{2}-\mathrm{Naph}-$ dG. Since the fidelity of Dpo4 bypass of $\mathrm{N}^{2}-\mathrm{CH}_{2}-\mathrm{Naph}-\mathrm{dG}$ is only diminished $\sim 2$-fold relative to $\mathrm{dG}$, it seems likely that the productive conformation involves the anti oriented adduct paired in normal Watson-Crick mode with dCTP and that the crystal structures failed to reveal the true active conformation. These structural results are indicative of the conformational heterogeneity that most likely accompanies many DNA adduct bypass events.

Like Dpo4, all four human Y-family DNA polymerases show fairly remarkable tolerance of minor groove DNA adducts when compared to model replicative enzymes. The efficiency and fidelity of pol $\eta$ bypass are not reduced much by $\mathrm{N}^{2}$-bulk equal to or smaller than the $\mathrm{N}^{2}-\mathrm{CH}_{2}-\mathrm{Naph}$ $\mathrm{dG}$ adduct, but it is severely perturbed by $\mathrm{N}^{2}-\mathrm{dG}$ adducts larger than a methylenyl(9-anthracenyl) group in the minor groove [76-78, 80]. REV1 and pol $\kappa$ provide the most accurate and catalytically tolerant means of bypassing of minor groove bulk at the guanine $\mathrm{N}^{2}$ atom at least up to a benzo[a]pyrene group $\left(\mathrm{N}^{2}-\mathrm{CH}_{2}-\mathrm{BPdG}\right)$ (Figure 3) $[76,80]$ but probably for different molecular reasons. The REV1 catalytic efficiency $\left(k_{\mathrm{cat}} / K_{\mathrm{m}, \mathrm{dNTP}}\right)$ is barely reduced at all during dCTP insertion opposite $\mathrm{N}^{2}-\mathrm{CH}_{2}-\mathrm{BPdG}$ relative to $\mathrm{dG}[80]$, presumably due to the fact that REV1 uses the Nterminal domain called the "N-digit" to flip the template base out of the polymerase active site, which results in the pairing of dCTP opposite an arginine in the $\mathrm{N}$-digit. Pol $\kappa$, on the other hand, is most likely stabilizing the $\mathrm{N}^{2}$-(ar)alkyl dG adducts in the minor groove through an interaction with the $\mathrm{N}$-clasp. In contrast to the $\mathrm{N}$-digit of REV1 (which resides on the minor groove side of the DNA binding cleft), the $\mathrm{N}$-clasp sits on top of the polymerase active site [84]. An in vitro comparison of pol $\kappa$-catalyzed bypass of $\mathrm{N}^{2}-\mathrm{BPdG}$ and $\mathrm{N}^{6}$-BPdA adducts clearly showed that the minor groove $\mathrm{N}^{2}-\mathrm{BPdG}$ was bypassed efficiently (regardless of adduct stereochemistry), while $\mathrm{N}^{6}$-BPdA was a complete block to pol $\kappa$ activity [85]. The results from a recent molecular modeling study are consistent with the idea that the $\mathrm{N}$-clasp of pol $\kappa$ plays a central role in facilitating accurate bypass of $\mathrm{N}^{2}$-BPdG adducts [86]. The modeling work suggests that anti-oriented $\mathrm{N}^{2}-\mathrm{BPdG}$ is stabilized in the minor groove because there are close contacts with the $\mathrm{N}$-clasp if $\mathrm{N}^{2}-\mathrm{BPdG}$ is positioned in the major groove by adopting the syn-orientation. Moreover, there appears to be a phenylalanine residue conserved only in pol $\kappa$ (Phe151) and REV1 (Phe-543) that may form base-stacking 
interactions with the benzo[a]pyrene ring system, favoring minor groove stabilization during accurate bypass of the adduct.

Bypass of major groove $\mathrm{O}^{6}-(\mathrm{Ar})$ alkyl-dG DNA adducts, at least up to $\mathrm{O}^{6}$-benzyldG $\left(\mathrm{O}^{6}\right.$-BzdG), is performed efficiently by human pol $\iota$ (Figure 3 ) but this reaction is highly error-prone (i.e., insertion of dTTP is the major product for both $\mathrm{O}^{6}-\mathrm{MedG}$ and $\left.\mathrm{O}^{6}-\mathrm{BzdG}\right)$, and pol $\iota$ efficiency is decreased 300-fold by $\mathrm{O}^{6}$-PobdG [82]. Other DNA polymerases, including pol $\delta$ (with PCNA), are able to bypass adducts in the major groove but the catalytic efficiency of these events appears to be more perturbed than with pol ı. Human replicative pol $\delta$ (with PCNA) appears to better accommodate and bypass major groove $\mathrm{O}^{6}$-BzG adducts [82] than minor groove $\mathrm{N}^{2}-\mathrm{BzG}$ adducts $[77-80,82]$. In contrast, most of human Y-family DNA polymerases except for pol $\iota$ can bypass minor groove $\mathrm{N}^{2}-\mathrm{G}$ adducts [76-80] much more efficiently than major groove $\mathrm{O}^{6}-\mathrm{G}$ adducts [82]. Human pol $\kappa$ was found to be the DNA polymerase most inhibited by the major groove-protruding $\mathrm{O}^{6}-(\mathrm{Ar})$ alkyl dG adducts, consistent with the $\mathrm{N}^{6}$-BPdA results and further suggesting a role for the $\mathrm{N}$-clasp in pol $\kappa$ functionality. Dpo 4 can bypass $\mathrm{O}^{6}$-MedG and $\mathrm{O}^{6}$-BzdG adducts in a catalytically perturbed (i.e., the efficiency is decreased 14- to 62-fold for each of the adducts) but mostly accurate manner $(\sim 70 \%$ accurate insertion of dCTP) $[87,88]$. The efficiency of Dpo4-catalyzed bypass of bulky $\mathrm{N}^{6}$-adenyl polycyclic aromatic hydrocarbon (PAH) adducts is reduced several hundred fold and results in a mixture of error-free and error-prone products [89]. By way of comparison, the high-fidelity bacteriophage $\mathrm{T}^{-}$ DNA polymerase is inhibited over 2,000-fold by $\mathrm{N}^{6}$-dA-PAH adducts [90]. Crystal structures of Dpo4 in complex with $\mathrm{O}^{6}$-(Ar)alkyl-dG modified DNA reveal that accurate bypass of these adducts proceeds through a "wobble" base pairing between $\mathrm{dC}$ and the $\mathrm{O}^{6}-(\mathrm{ar})$ alkyl-dG adduct. Work with the $(+)$-trans and $(-)$-trans- $\mathrm{N}^{6}$-BPdA adducts indicated that human pol $\eta$ was quite efficient at bypassing the $(+)$-trans stereoisomer in what appears to be an accurate manner but was essentially blocked by the (-)-trans stereoisomer of the $\mathrm{N}^{6}$-BPdA adduct [85]. The exact structural rationale for the results with pol $\eta$ and major groove $\mathrm{dA}$ adducts remains unknown. Interestingly, pol $\eta$ but not pol $\iota$ nor $\kappa$ can copy past $\mathrm{O}^{6}$-PobdG [82] as well as the $C^{8}$-dG adduct of 2-amino3-methylimidazo[4,5-f] quinoline (IQ) [61], indicating the versatile bypass activity of pol $\eta$ past various DNA lesions such as major and minor groove DNA adducts, ring-closed exocyclic DNA adducts (vide infra), as well as pyrimidine dimers.

\section{Exocyclic DNA Adducts}

Exocyclic DNA adducts can be formed through many of the same chemical and biological processes that form major/minor groove adducts, namely, electrophilic lipid oxidation products and products arising from oxidation of DNA $[73,91]$. Of particular interest is the $3-\left(2^{\prime}\right.$-deoxy- $\beta$-Derythro-pentofuranosyl)pyrimido[1,2-a]purin-10(3H)-one $\left(\mathrm{M}_{1} \mathrm{dG}\right)$ adduct (Figure $1(\mathrm{~d})$ ) arising from exposure to the bis-electrophile malondialdehyde or base propenals that arise following treatment with chemicals such as bleomycin [92-94]. The $\mathrm{M}_{1} \mathrm{dG}$ adduct has been detected at levels of 5,400 adducts per liver cell in the DNA of healthy humans [95]. This adduct is a particularly insidious impediment to genomic integrity because it can ring-open when paired opposite cytosine in dsDNA [96], which may mask its presence from detection by DNA repair pathways. In single-stranded (ss) DNA, the ring-opened $\mathrm{N}^{2}$-oxopropenyl-2'-deoxyguanosine $\left(\mathrm{N}^{2}-\mathrm{OPdG}\right)$ form closes to $M_{1} d G$, blocking the Watson-Crick edge of the guanine base. $\mathrm{M}_{1} \mathrm{dG}$ is mutagenic in both bacterial and mammalian cells, producing mainly $G$ to $T$ transversions but also resulting in -1 frameshift deletions [97]. Studies with Y-family DNA polymerases indicate that pol $\eta$ is the most likely candidate for producing the $\mathrm{G}$ to $\mathrm{T}$ transverions in mammalian systems (Figure 3) [98]. Both pols $\iota$ and $\kappa$ are relatively accurate when bypassing $\mathrm{M}_{1} \mathrm{dG}$, and while pol $\kappa$ showed preferential insertion of dCTP there was a strong level of inhibition relative to catalysis opposite dG (Maddukuri, L., Eoff, R.L., Choi, J-Y., Rizzo, C. J., Guengerich, F. P., and Marnett, L.J., Biochemistry in press). Crystal structures have been solved with Dpo4 in complex with $\mathrm{M}_{1} \mathrm{dG}$ modified template DNA [99]. Like human pol $\eta$, Dpo4 preferentially inserts dATP opposite $\mathrm{M}_{1} \mathrm{dG}$, although the catalytic efficiency of this reaction is diminished 260to 430 -fold relative to normal insertion of dCTP opposite template $\mathrm{dG}$. The $\mathrm{M}_{1} \mathrm{dG}$ adduct is in the ring-closed form in both Dpo4 ternary structures reported, even though the primer in one complex was designed to pair a $3^{\prime}$-terminal cytosine residue with $\mathrm{M}_{1} \mathrm{dG}$.

$1, \mathrm{~N}^{2}$-Etheno $(\varepsilon) \mathrm{dG}$ (Figure $1(\mathrm{~d})$ ) is another mutagenic exocyclic DNA adduct formed through the reaction of DNA with reactive chemicals (e.g., epoxides formed from oxidation of vinyl chloride and urethane) and endogenous products of lipid peroxidation [100-103]. The $1, \mathrm{~N}^{2}-\mathcal{E}-$ $\mathrm{dG}$ adduct, like the ring-closed $\mathrm{M}_{1} \mathrm{dG}$ adduct, blocks the Watson-Crick edge of guanine. Similar to $\mathrm{M}_{1} \mathrm{dG}$ bypass, human pols $\eta$ and $\iota$ can bypass $1, N^{2}-\varepsilon-d G$ and generate misinsertion errors ( $\mathrm{G}$ and $\mathrm{T}$, resp.), but pol $\kappa$ was severely inhibited in catalysis [76]. Biochemical studies with Dpo4 showed that the major products arising from bypass of $1, \mathrm{~N}^{2}-\varepsilon-\mathrm{dG}$ are dATP misinsertions and -1 frameshift deletions [104]. In the same study, crystal structures revealed that Dpo4 readily skips past the $1, \mathrm{~N}^{2}-\varepsilon-\mathrm{d} G$ adduct with no major perturbations to the polymerase active site. A similar so-called "type II" structure was solved for Dpo4 in complex with $\mathrm{M}_{1} \mathrm{dG}$-containing template DNA [99]. As noted earlier, there are no hydrogen bonds between the purine/pyrimidine rings of the nascent base pair and amino acid side chains in the Dpo4 active site to influence base pair geometry. Recent work has highlighted the importance of base-stacking between the primer-template junction and the nascent base pair during Dpo4-catalyzed generation of -1 frameshift deletions [83]. Presumably the same phenomenon is playing a significant role in determining the outcome of Dpo4-catalyzed bypass of exocyclic DNA adducts and perhaps other Y-family DNA polymerases. 


\section{Summary and Outlook}

Many questions remain regarding the biological importance of individual DNA polymerases during bypass of specific DNA lesions. In vitro experimentation with purified recombinant enzymes can certainly establish what is possible in nature but may not represent what is most likely to occur in vivo. The mechanisms that regulate how and when specialized DNA polymerases gain access to damaged template DNA are complex, and many elements of these pathways remain to be elucidated. Mechanistic studies related to adduct bypass in different sequence contexts might also be very helpful in developing a greater understanding of mutations hotspots and the relationship of mutations to cancer. Finally, the importance of Yfamily DNA polymerases in the processing of non-B form DNA is an area of active interest because these types of structures are intimately linked to the manifestation of fragile sites in the genome, as well as in rearrangements that occur in the promoter regions of tumor suppressors and oncogenes.

\section{Abbreviations}

\begin{tabular}{|c|c|}
\hline G: & Guanine \\
\hline A: & Adenine \\
\hline $\mathrm{C}:$ & Cytosine \\
\hline dG: & $2^{\prime}$-deoxyguanosine \\
\hline THF: & Tetrahydrofuran \\
\hline 8-oxodG: & $\begin{array}{l}\text { 7,8-dihydro-8-oxo- } 1^{\prime} \text { - } \\
\text { deoxyguanosine }\end{array}$ \\
\hline dNTP: & Deoxynucleoside triphosphate \\
\hline pol: & DNA polymerase \\
\hline Dpo4: & $\begin{array}{l}\text { Sulfolobus solfataricus DNA } \\
\text { Polymerase IV }\end{array}$ \\
\hline PCNA: & Proliferating cell nuclear antigen \\
\hline RFC: & Replication factor C \\
\hline RPA: & Replication protein A \\
\hline PAH: & Polycyclic aromatic hydrocarbon \\
\hline BP: & Benzo $[a]$ pyrene \\
\hline Me: & Methyl \\
\hline Et: & Ethyl \\
\hline Ib: & Isobutyl \\
\hline Bz: & Benzyl \\
\hline $\mathrm{N}^{2}-\mathrm{CH}_{2}-\mathrm{Naph}:$ & $\mathrm{N}^{2}$-methylenyl(2-naphthyl) \\
\hline $\mathrm{N}^{2}-\mathrm{CH}_{2}$-Anth: & $\mathrm{N}^{2}$-methylenyl(9-anthracenyl) \\
\hline $\mathrm{N}^{2}-\mathrm{CH}_{2}-\mathrm{BP}:$ & $\mathrm{N}^{2}$-methylenyl $(6$-benzo $[a]$ \\
\hline & Pyrenyl) \\
\hline Pob: & 4-oxo-4-(3-pyridyl)butyl \\
\hline $\operatorname{exo}^{-}:$ & Exonuclease deficient \\
\hline IQ: & $\begin{array}{l}\text { 2-amino-3-methylimidazo }[4,5-f] \\
\text { quinoline(IQ) }\end{array}$ \\
\hline $\mathrm{M}_{1} \mathrm{dG}:$ & 3- $\left(2^{\prime}\right.$-deoxy- $\beta$-D-erythro- \\
\hline & Pentofuranosyl)pyrimido $[1,2-a]$ \\
\hline & Purin-10(3H)-one \\
\hline $\mathrm{N}^{2}-\mathrm{OP}:$ & $\mathrm{N}^{2}$-oxopropenyl \\
\hline ds: & Double-stranded \\
\hline ss: & Single-stranded \\
\hline $1, \mathrm{~N}^{2}-\varepsilon:$ & 1, $\mathrm{N}^{2}$-etheno. \\
\hline
\end{tabular}

\section{Acknowledgment}

This work was supported in part by United States Public Health Service Grants R01 ES010375 (F.P.G.), K99 GM084460 (R.L.E.), and P30 ES000267 (F.P.G.).

\section{References}

[1] U. Hübscher, G. Maga, and S. Spadari, "Eukaryotic DNA polymerases," Annual Review of Biochemistry, vol. 71, pp. 133-163, 2002.

[2] C. M. Joyce and T. A. Steitz, "Function and structure relationships in DNA polymerases," Annual Review of Biochemistry, vol. 63, pp. 777-822, 1994.

[3] L. A. Loeb and R. J. Monnat Jr., "DNA polymerases and human disease," Nature Reviews Genetics, vol. 9, no. 8, pp. 594-604, 2008.

[4] K. A. Johnson, "The kinetic and chemical mechanism of high-fidelity DNA polymerases," Biochimica et Biophysica Acta, vol. 1804, no. 5, pp. 1041-1048, 2010.

[5] D. J. Chang and K. A. Cimprich, "DNA damage tolerance: when it's OK to make mistakes," Nature Chemical Biology, vol. 5, no. 2, pp. 82-90, 2009.

[6] E. C. Friedberg, G. C. Walker, W. Siede, R. D. Wood, R. A. Shultz, and T. Ellenberger, DNA Repair and Mutagenesis, ASM Press, Washington, DC, USA, 2nd edition, 2006.

[7] N. Geacintov and S. Broyde, Eds., The Chemical Biology of DNA Damage, Wiley-VCH, Weinheim, Germany, 2010.

[8] B. N. Ames, "Identifying environmental chemicals causing mutations and cancer," Science, vol. 204, no. 4393, pp. 587593, 1979.

[9] P. D. Lawley, "Chemical Carcinogens," in Chemical Carcinogens, C. E. Searle, Ed., pp. 325-484, American Chemical Society, Washington, DC, USA, 1984.

[10] C. M. Joyce and S. J. Benkovic, "DNA polymerase fidelity: kinetics, structure, and checkpoints," Biochemistry, vol. 43, no. 45, pp. 14317-14324, 2004.

[11] N. Sabouri, J. Viberg, D. K. Goyal, E. Johansson, and A. Chabes, "Evidence for lesion bypass by yeast replicative DNA polymerases during DNA damage," Nucleic Acids Research, vol. 36, no. 17, pp. 5660-5667, 2008.

[12] M. W. Schmitt, Y. Matsumoto, and L. A. Loeb, "High fidelity and lesion bypass capability of human DNA polymerase $\delta$," Biochimie, vol. 91, no. 9, pp. 1163-1172, 2009.

[13] F. P. Guengerich, "Interactions of carcinogen-bound DNA with individual DNA polymerases," Chemical Reviews, vol. 106, no. 2, pp. 420-452, 2006.

[14] W. Yang and R. Woodgate, "What a difference a decade makes: Insights into translesion DNA synthesis," Proceedings of the National Academy of Sciences of the United States of America, vol. 104, no. 40, pp. 15591-15598, 2007.

[15] J. P. McDonald, A. S. Levine, and R. Woodgate, "The Saccharomyces cerevisiae RAD30 gene, a homologue of Escherichia coli dinB and umuC, is DNA damage inducible and functions in a novel error-free postreplication repair mechanism," Genetics, vol. 147, no. 4, pp. 1557-1568, 1997.

[16] S. G. Kozmin, Y. I. Pavlov, T. A. Kunkel, and E. Sage, "Roles of Saccharomyces cerevisiae DNA polymerases Pol $\eta$ and Pol $\zeta$ in response to irridiation by simulated sunlight," Nucleic Acids Research, vol. 31, no. 15, pp. 4541-4552, 2003. 
[17] M. R. Albertella, C. M. Green, A. R. Lehmann, and M. J. O'Connor, "A role for polymerase $\eta$ in the cellular tolerance to cisplatin-induced damage," Cancer Research, vol. 65, no. 21, pp. 9799-9806, 2005.

[18] M. R. Albertella, A. Lau, and M. J. O'Connor, "The overexpression of specialized DNA polymerases in cancer," DNA Repair, vol. 4, no. 5, pp. 583-593, 2005.

[19] A. Alt, K. Lammens, C. Chiocchini et al., "Bypass of DNA lesions generated during anticancer treatment with cisplatin by DNA polymerase $\eta$," Science, vol. 318, no. 5852, pp. 967970, 2007.

[20] C. Bavoux, J. S. Hoffmann, and C. Cazaux, "Adaptation to DNA damage and stimulation of genetic instability: the double-edged sword mammalian DNA polymerase $\kappa$," Biochimie, vol. 87, no. 7, pp. 637-646, 2005.

[21] C. Bavoux, A. M. Leopoldino, V. Bergoglio et al., "Upregulation of the error-prone DNA polymerase $\kappa$ promotes pleiotropic genetic alterations and tumorigenesis," Cancer Research, vol. 65, no. 1, pp. 325-330, 2005.

[22] F. Lemée, C. Bavoux, M. J. Pillaire et al., "Characterization of promoter regulatory elements involved in downexpression of the DNA polymerase $\kappa$ in colorectal cancer," Oncogene, vol. 26, no. 23, pp. 3387-3394, 2007.

[23] A. Tissier, J. P. McDonald, E. G. Frank, and R. Woodgate, "polı, a remarkably error-prone human DNA polymerase," Genes and Development, vol. 14, no. 13, pp. 1642-1650, 2000.

[24] J. Yang, Z. Chen, Y. Liu, R. J. Hickey, and L. H. Malkas, "Altered DNA polymerase $\iota$ expression in breast cancer cells leads to a reduction in DNA replication fidelity and a higher rate of mutagenesis," Cancer Research, vol. 64, no. 16, pp. 5597-5607, 2004.

[25] C. Biertumpfel, Y. Zhao, Y. Kondo et al., "Structure and mechanism of human DNA polymerase $\eta$," Nature, vol. 465, no. 7301, pp. 1044-1048, 2010.

[26] C. Masutani, R. Kusumoto, A. Yamada et al., "The XPV (xeroderma pigmentosum variant) gene encodes human DNA polymerase $\eta$," Nature, vol. 399, no. 6737, pp. 700-704, 1999.

[27] T. D. Silverstein, R. E. Johnson, R. Jain, L. Prakash, S. Prakash, and A. K. Aggarwal, "Structural basis for the suppression of skin cancers by DNA polymerase $\eta$," Nature, vol. 465, no. 7301, pp. 1039-1043, 2010.

[28] M. T. Washington, L. Prakash, and S. Prakash, "Mechanism of nucleotide incorporation opposite a thymine-thymine dimer by yeast DNA polymerase $\eta$," Proceedings of the National Academy of Sciences of the United States of America, vol. 100, no. 21, pp. 12093-12098, 2003.

[29] T. Lindahl and B. Nyberg, "Rate of depurination of native deoxyribonucleic acid," Biochemistry, vol. 11, no. 19, pp. 3610-3618, 1972.

[30] J. Nakamura, V. E. Walker, P. B. Upton, S.-Y. Chiang, Y. W. Kow, and J. A. Swenberg, "Highly sensitive apurinic/apyrimidinic site assay can detect spontaneous and chemically induced depurination under physiological conditions," Cancer Research, vol. 58, no. 2, pp. 222-225, 1998.

[31] D. E. Barnes and T. Lindahl, "Repair and genetic consequences of endogenous DNA base damage in mammalian cells," Annual Review of Genetics, vol. 38, pp. 445-476, 2004.

[32] L. A. Loeb and B. D. Preston, "Mutagenesis by apurinic/apyrimidinic sites," Annual Review of Genetics, vol. 20, pp. 201-230, 1986.
[33] S. Shibutani, M. Takeshita, and A. P. Grollman, "Translesional synthesis on DNA templates containing a single abasic site: a mechanistic study of the "a rule"', Journal of Biological Chemistry, vol. 272, no. 21, pp. 13916-13922, 1997.

[34] M. Tang, P. Pham, X. Shen et al., "Roles of E. coli DNA polymerases IV and $\mathrm{V}$ in lesion-targeted and untargeted SOS mutagenesis," Nature, vol. 404, no. 6781, pp. 1014-1018, 2000.

[35] P. E. M. Gibbs, J. McDonald, R. Woodgate, and C. W. Lawrence, "The relative roles in vivo of Saccharomyces cerevisiae Pol $\eta$, Pol $\zeta$, Rev1 protein and Pol32 in the bypass and mutation induction of an abasic site, T-T (6-4) photoadduct and T-T cis-syn cyclobutane dimer," Genetics, vol. 169, no. 2, pp. 575-582, 2005.

[36] L. Haracska, I. Unk, R. E. Johnson et al., "Roles of yeast DNA polymerases $\delta$ and $\zeta$ and Rev 1 in the bypass of abasic sites," Genes and Development, vol. 15, no. 8, pp. 945-954, 2001.

[37] N. Sabouri and E. Johansson, "Translesion synthesis of abasic sites by yeast DNA polymerase $\varepsilon$," Journal of Biological Chemistry, vol. 284, no. 46, pp. 31555-31563, 2009.

[38] F. Boudsocq, S. Iwai, F. Hanaoka, and R. Woodgate, "Sulfolobus solfataricus P2 DNA polymerase IV (Dpo4): an archaeal DinB-like DNA polymerase with lesion-bypass properties akin to eukaryotic poln," Nucleic Acids Research, vol. 29, no. 22, pp. 4607-4616, 2001.

[39] L. Haracska, M. T. Washington, S. Prakash, and L. Prakash, "Inefficient bypass of an abasic site by DNA polymerase $\eta$," Journal of Biological Chemistry, vol. 276, no. 9, pp. 68616866, 2001.

[40] L. Haracska, I. Unk, R. E. Johnson et al., "Stimulation of DNA synthesis activity of human DNA polymerase $\kappa$ by PCNA," Molecular and Cellular Biology, vol. 22, no. 3, pp. 784-791, 2002.

[41] R. E. Johnson, M. T. Washington, L. Haracska, S. Prakash, and L. Prakash, "Eukaryotic polymerases $\iota$ and $\zeta$ act sequentially to bypass DNA lesions," Nature, vol. 406, no. 6799, pp. 1015-1019, 2000.

[42] M. K. Swan, R. E. Johnson, L. Prakash, S. Prakash, and A. K. Aggarwal, "Structural basis of high-fidelity DNA synthesis by yeast DNA polymerase $\delta$," Nature Structural and Molecular Biology, vol. 16, no. 9, pp. 979-986, 2009.

[43] H. Ling, F. Boudsocq, R. Woodgate, and W. Yang, "Crystal structure of a Y-family DNA polymerase in action: a mechanism for error-prone and lesion-bypass replication," Cell, vol. 107, no. 1, pp. 91-102, 2001.

[44] C. Otsuka, S. Sanadai, Y. Hata et al., "Difference between deoxyribose- and tetrahydrofuran-type abasic sites in the in vivo mutagenic responses in yeast," Nucleic Acids Research, vol. 30, no. 23, pp. 5129-5135, 2002.

[45] D. T. Nair, R. E. Johnson, L. Prakash, S. Prakash, and A. K. Aggarwal, "Biochemistry: revl employs a novel mechanism of DNA synthesis using a protein template," Science, vol. 309, no. 5744, pp. 2219-2222, 2005.

[46] B. N. Ames, "Dietary carcinogens and anticarcinogens. Oxygen radicals and degenerative diseases," Science, vol. 221, no. 4617, pp. 1256-1263, 1983.

[47] M. Valko, H. Morris, and M. T. D. Cronin, "Metals, toxicity and oxidative stress," Current Medicinal Chemistry, vol. 12, no. 10, pp. 1161-1208, 2005.

[48] C. G. Fraga, M. K. Shigenaga, J.-W. Park, P. Degan, and B. N. Ames, "Oxidative damage to DNA during aging: 8-Hydroxy2'-deoxyguanosine in rat organ DNA and urine," Proceedings of the National Academy of Sciences of the United States of America, vol. 87, no. 12, pp. 4533-4537, 1990. 
[49] M. Abul Kalam, K. Haraguchi, S. Chandani et al., "Genetic effects of oxidative DNA damages: comparative mutagenesis of the imidazole ring-opened formamidopyrimidines (Fapy lesions) and 8-oxo-purines in simian kidney cells," Nucleic Acids Research, vol. 34, no. 8, pp. 2305-2315, 2006.

[50] S. Boiteux and J. P. Radicella, "The human OGG1 gene: structure, functions, and its implication in the process of carcinogenesis," Archives of Biochemistry and Biophysics, vol. 377, no. 1, pp. 1-8, 2000.

[51] M. L. Michaels, C. Cruz, A. P. Grollman, and J. H. Miller, "Evidence that MutY and MutM combine to prevent mutations by an oxidatively damaged form of guanine in DNA," Proceedings of the National Academy of Sciences of the United States of America, vol. 89, no. 15, pp. 7022-7025, 1992.

[52] M. L. Michaels and J. H. Miller, "The GO system protects organisms from the mutagenic effect of the spontaneous lesion 8-hydroxyguanine (7,8-dihydro-8-oxoguanine)," Journal of Bacteriology, vol. 174, no. 20, pp. 6321-6325, 1992.

[53] M. L. Michaels, J. Tchou, A. P. Grollman, and J. H. Miller, "A repair system for 8-oxo-7,8-dihydrodeoxyguanine," Biochemistry, vol. 31, no. 45, pp. 10964-10968, 1992.

[54] M. P. Gallego and A. Sarasin, "Transcription-coupled repair of 8-oxoguanine in human cells and its deficiency in some DNA repair diseases," Biochimie, vol. 85, no. 11, pp. 10731082, 2003.

[55] L. G. Brieba, B. F. Eichman, R. J. Kokoska, S. Doublié, T. A. Kunkel, and T. Ellenberger, "Structural basis for the dual coding potential of 8-oxoguanosine by a high-fidelity DNA polymerase," EMBO Journal, vol. 23, no. 17, pp. 3452-3461, 2004.

[56] H. J. Einolf and F. P. Guengerich, "Fidelity of nucleotide insertion at 8-oxo-7,8-dihydroguanine by mammalian DNA polymerase $\delta$ : steady-state and pre-steady-state kinetic analysis," Journal of Biological Chemistry, vol. 276, no. 6, pp. 3764-3771, 2001.

[57] H. J. Einolf, N. Schnetz-Boutaud, and F. P. Guengerich, "Steady-state and pre-steady-state kinetic analysis of 8oxo-7,8- dihydroguanosine triphosphate incorporation and extension by replicative and repair DNA polymerases," Biochemistry, vol. 37, no. 38, pp. 13300-13312, 1998.

[58] L. L. Furge and F. P. Guengerich, "Analysis of nucleotide insertion and extension at 8-oxo-7,8- dihydroguanine by replicative T7 polymerase exo- and human immunodeficiency virus-1 reverse transcriptase using steady-state and pre-steady-state kinetics," Biochemistry, vol. 36, no. 21, pp. 6475-6487, 1997.

[59] L. G. Lowe and F. P. Guengerich, "Steady-state and presteady-state kinetic analysis of dNTP insertion opposite 8oxo-7,8-dihydroguanine by Escherichia coli I exo- and II exo," Biochemistry, vol. 35, no. 30, pp. 9840-9849, 1996.

[60] S. Shibutani, M. Takeshita, and A. P. Grollman, "Insertion of specific bases during DNA synthesis past the oxidationdamaged base 8-oxodG," Nature, vol. 349, no. 6308, pp. 431434, 1991.

[61] K. D. Carlson and M. T. Washington, "Mechanism of efficient and accurate nucleotide incorporation opposite 7,8-dihydro8 -oxoguanine by Saccharomyces cerevisiae DNA polymerase $\eta$," Molecular and Cellular Biology, vol. 25, no. 6, pp. 21692176, 2005.

[62] L. Haracska, S.-L. Yu, R. E. Johnson, L. Prakash, and S. Prakash, "Efficient and accurate replication in the presence of 7,8-dihydro-8-oxoguanine by DNA polymerase $\eta$," Nature Genetics, vol. 25, no. 4, pp. 458-461, 2000.
[63] G. Maga, G. Villani, E. Crespan et al., "8-oxo-guanine bypass by human DNA polymerases in the presence of auxiliary proteins," Nature, vol. 447, no. 7144, pp. 606-608, 2007.

[64] R. L. Eoff, A. Irimia, K. C. Angel, M. Egli, and F. P. Guengerich, "Hydrogen bonding of 7,8-dihydro-8oxodeoxyguanosine with a charged residue in the little finger domain determines miscoding events in sulfolobus solfataricus DNA polymerase Dpo4," Journal of Biological Chemistry, vol. 282, no. 27, pp. 19831-19843, 2007.

[65] O. Rechkoblit, L. Malinina, Y. Cheng et al., "Stepwise translocation of Dpo4 polymerase during error-free bypass of an oxoG lesion," PLoS Biology, vol. 4, no. 1, p. e11, 2006.

[66] H. Zang, A. Irimia, J.-Y. Choi et al., "Efficient and high fidelity incorporation of dCTP opposite 7,8-dihydro-8oxodeoxyguanosine by Sulfolobus solfataricus DNA polymerase Dpo4," Journal of Biological Chemistry, vol. 281, no. 4, pp. 2358-2372, 2006.

[67] A. Vaisman and R. Woodgate, "Unique misinsertion specificity of por may decrease the mutagenic potential of deaminated cytosines," EMBO Journal, vol. 20, no. 22, pp. 6520-6529, 2001.

[68] Y. Zhang, X. Wu, O. Rechkoblit, N. E. Geacintov, J.-S. Taylor, and Z. Wang, "Response of human REV1 to different DNA damage: preferential dCMP insertion opposite the lesion," Nucleic Acids Research, vol. 30, no. 7, pp. 1630-1638, 2002.

[69] S. Uesugi and M. Ikehara, "Carbon-13 magnetic resonance spectra of 8-substituted purine nucleosides. Characteristic shifts for the syn conformation," Journal of the American Chemical Society, vol. 99, no. 10, pp. 3250-3253, 1977.

[70] A. Irimia, R. L. Eoff, F. P. Guengerich, and M. Egli, "Structural and functional elucidation of the mechanism promoting error-prone synthesis by human DNA polymerase $\kappa$ opposite the 7,8-dihydro-8-oxo-2'-deoxyguanosine adduct," Journal of Biological Chemistry, vol. 284, no. 33, pp. 22467-22480, 2009.

[71] M. Hogg, S. S. Wallace, and S. Doublié, "Bumps in the road: how replicative DNA polymerases see DNA damage," Current Opinion in Structural Biology, vol. 15, no. 1, pp. 86-93, 2005.

[72] S. C. Cheng, B. D. Hilton, J. M. Roman, and A. Dipple, "DNA adducts from carcinogenic and noncarcinogenic enantiomers of benzo [a]pyrene dihydrodiol epoxide," Chemical Research in Toxicology, vol. 2, no. 5, pp. 334-340, 1989.

[73] M. H. G. Medeiros, "Exocyclic DNA adducts as biomarkers of lipid oxidation and predictors of disease. Challenges in developing sensitive and specific methods for clinical studies," Chemical Research in Toxicology, vol. 22, no. 3, pp. 419-425, 2009.

[74] T. Meehan and K. Straub, "Double stranded DNA stereoselectively binds benzo(a)pyrene diol epoxides," Nature, vol. 277, no. 5695, pp. 410-412, 1979.

[75] I. G. Minko, I. D. Kozekov, T. M. Harris, C. J. Rizzo, R. S. Lloyd, and M. P. Stone, "Chemistry and biology of DNA containing $1, N^{2}$-deoxyguanosine adducts of the $\alpha, \beta$-unsaturated aldehydes acrolein, crotonaldehyde, and 4hydroxynonenal," Chemical Research in Toxicology, vol. 22, no. 5, pp. 759-778, 2009.

[76] J.-Y. Choi, K. C. Angel, and F. P. Guengerich, "Translesion synthesis across bulky $\mathrm{N}^{2}$-alkyl guanine DNA adducts by human DNA polymerase $\kappa$," Journal of Biological Chemistry, vol. 281, no. 30, pp. 21062-21072, 2006.

[77] J.-Y. Choi and F. P. Guengerich, "Analysis of the effect of bulk at $N^{2}$-alkylguanine DNA adducts on catalytic efficiency and fidelity of the processive DNA polymerases bacteriophage 
T7 exonuclease- and HIV-1 reverse transcriptase," Journal of Biological Chemistry, vol. 279, no. 18, pp. 19217-19229, 2004.

[78] J.-Y. Choi and F. P. Guengerich, "Adduct size limits efficient and error-free bypass across bulky $N^{2}$-guanine DNA lesions by human DNA polymerase $\eta$," Journal of Molecular Biology, vol. 352, no. 1, pp. 72-90, 2005.

[79] J.-Y. Choi and F. P. Guengerich, "Kinetic evidence for inefficient and error-prone bypass across bulky $N^{2}$-guanine DNA adducts by human DNA polymerase," Journal of Biological Chemistry, vol. 281, no. 18, pp. 12315-12324, 2006.

[80] J.-Y. Choi and F. P. Guengerich, "Kinetic analysis of translesion synthesis opposite bulky $N^{2}$ - and $O^{6}$-alkylguanine DNA adducts by human DNA polymerase REV1," Journal of Biological Chemistry, vol. 283, no. 35, pp. 23645-23655, 2008.

[81] K. S. Gates, "An overview of chemical processes that damage cellular DNA: spontaneous hydrolysis, alkylation, and reactions with radicals," Chemical Research in Toxicology, vol. 22, no. 11, pp. 1747-1760, 2009.

[82] J.-Y. Choi, G. Chowdhury, H. Zang et al., "Translesion synthesis across $O^{6}$-alkylguanine DNA adducts by recombinant human DNA polymerases," Journal of Biological Chemistry, vol. 281, no. 50, pp. 38244-38256, 2006.

[83] H. Zhang, R. L. Eoff, I. D. Kozekov, C. J. Rizzo, M. Egli, and F. P. Guengerich, "Versatility of y-family Sulfolobus solfataricus DNA polymerase Dpo4 in translesion synthesis past bulky $N^{2}$-alkylguanine adducts," Journal of Biological Chemistry, vol. 284, no. 6, pp. 3563-3576, 2009.

[84] S. Lone, S. A. Townson, S. N. Uljon et al., "Human DNA polymerase kappa encircles DNA: implications for mismatch extension and lesion bypass," Molecular Cell, vol. 25, no. 4, pp. 601-614, 2007.

[85] O. Rechkoblit, Y. Zhang, D. Guo et al., "trans-lesion synthesis past bulky benzo[a]pyrene diol epoxide $N^{2}$-dG and $N^{6}$-dA lesions catalyzed by DNA bypass polymerases," Journal of Biological Chemistry, vol. 277, no. 34, pp. 30488-30494, 2002.

[86] L. Jia, N. E. Geacintov, and S. Broyde, "The N-clasp of human DNA polymerase $\kappa$ promotes blockage or error-free bypass of adenine- or guanine-benzo[a]pyrenyl lesions," Nucleic Acids Research, vol. 36, no. 20, pp. 6571-6584, 2008.

[87] R. L. Eoff, K. C. Angel, M. Egli, and F. P. Guengerich, "Molecular basis of selectivity of nucleoside triphosphate incorporation opposite $O^{6}$-benzylguanine by Sulfolobus solfataricus DNA polymerase Dpo4: steady-state and presteady-state kinetics and X-ray crystallography of correct and incorrect pairing," Journal of Biological Chemistry, vol. 282, no. 18, pp. 13573-13584, 2007.

[88] R. L. Eoff, A. Irimia, M. Egli, and F. P. Guengerich, "Sulfolobus solfataricus DNA polymerase Dpo4 is partially inhibited by "Wobble" pairing between $O^{6}$-methylguanine and cytosine, but accurate bypass is preferred," Journal of Biological Chemistry, vol. 282, no. 2, pp. 1456-1467, 2007.

[89] H. Zang, G. Chowdhury, K. C. Angel, T. M. Harris, and F. P. Guengerich, "Translesion synthesis across polycyclic aromatic hydrocarbon diol epoxide adducts of deoxyadenosine by Sulfolobus solfataricus DNA polymerase Dpo4," Chemical Research in Toxicology, vol. 19, no. 6, pp. 859-867, 2006.

[90] H. Zang, T. M. Harris, and F. P. Guengerich, "Kinetics of nucleotide incorporation opposite polycyclic aromatic hydrocarbon-DNA adducts by processive bacteriophage T7 DNA polymerase," Chemical Research in Toxicology, vol. 18, no. 2, pp. 389-400, 2005.

[91] H. Bartsch and B. Singer, Eds., Exocyclic DNA Adducts in Mutagenesis and Carcinogenesis, vol. 150, IARC Scientific
Publications, International Agency for Research on Cancer, Lyon, France, 1999.

[92] A. K. Basu, S. M. O’Hara, P. Valladier, K. Stone, O. Mols, and L. J. Marnett, "Identification of adducts formed by reaction of guanine nucleosides with malondialdehyde and structurally related aldehydes," Chemical Research in Toxicology, vol. 1, no. 1, pp. 53-59, 1988.

[93] P. C. Dedon, J. P. Plastaras, C. A. Rouzer, and L. J. Marnett, "Indirect mutagenesis by oxidative DNA damage: formation of the pyrimidopurinone adduct of deoxyguanosine by base propenal," Proceedings of the National Academy of Sciences of the United States of America, vol. 95, no. 19, pp. 11113-11116, 1998.

[94] H. Seto, T. Okuda, T. Takesue, and T. Ikemura, "Reaction of malonaldehyde with nucleic acid. I. Formation of fluorescent pyrimido[1,2-a]purin-10(3H)-one nucleosides," Bulletin of the Chemical Society of Japan, vol. 56, no. 6, pp. 1799-1802, 1983.

[95] A. K. Chaudhary, M. Nokubo, L. J. Marnett, and I. A. Blair, "Analysis of the malondialdehyde-2'-deoxyguanosine adduct in rat liver DNA by gas chromatography/electron capture negative chemical ionization mass spectrometry," Biological Mass Spectrometry, vol. 23, no. 8, pp. 457-464, 1994.

[96] H. Mao, N. C. Schnetz-Boutaud, J. P. Weisenseel, L. J. Marnett, and M. P. Stone, "Duplex DNA catalyzes the chemical rearrangement of a malondialdehyde deoxyguanosine adduct," Proceedings of the National Academy of Sciences of the United States of America, vol. 96, no. 12, pp. 6615-6620, 1999.

[97] L. A. VanderVeen, M. F. Hashim, Y. Shyr, and L. J. Marnett, "Induction of frameshift and base pair substitution mutations by the major DNA adduct of the endogenous carcinogen malondialdehyde," Proceedings of the National Academy of Sciences of the United States of America, vol. 100, no. 2, pp. 14247-14252, 2003.

[98] J. B. Stafford, R. L. Eoff, A. Kozekova, C. J. Rizzo, P. Guengerich, and L. J. Marnett, "Translesion DNA synthesis by human DNA polymerase $\eta$ on templates containing a pyrimidopurinone deoxyguanosine Adduct, 3- $\left(2^{\prime}-\operatorname{deoxy}-\beta\right.$ D-erythro- pentofuranosyl)pyrimido-[1,2-a]purin-10(3H)one," Biochemistry, vol. 48, no. 2, pp. 471-480, 2009.

[99] R. L. Eoff, J. B. Stafford, J. Szekely et al., "Structural and functional analysis of Sulfolobus solfataricus Y-family DNA polymerase Dpo4-catalyzed bypass of the malondialdehydedeoxyguanosine adduct," Biochemistry, vol. 48, no. 30, pp. 7079-7088, 2009.

[100] F. P. Guengerich, S. Langouët, A. N. Mican, S. Akasaka, M. Müller, and M. Persmark, "Formation of etheno adducts and their effects on DNA polymerases," in Exocyclic DNA Adducts in Mutagenesis and Carcinogenesis, B. Singer and H. Bartsch, Eds., vol. 150, pp. 137-145, IARC Scientific Publications, International Agency for Research on Cancer, Lyon, France, 1999.

[101] F. P. Guengerich, M. Persmark, and W. G. Humphreys, "Formation of $1, N^{2}$ - and $N^{2}, 3$-ethenoguanine from 2halooxiranes: isotopic labeling studies and isolation of a hemiaminal derivative of $\mathrm{N}^{2}$-(2-oxoethyl)guanine," Chemical Research in Toxicology, vol. 6, no. 5, pp. 635-648, 1993.

[102] S. S. Hecht, R. Young-Sciame, and F.-L. Chung, "Reaction of $\alpha$-acetoxy- $N$-nitrosopiperidine with deoxyguanosine: oxygen- dependent formation of 4-oxo-2-pentenal and a $1, N^{2}$-ethenodeoxyguanosine adduct," Chemical Research in Toxicology, vol. 5, no. 5, pp. 706-712, 1992. 
[103] R. S. Sodum and F.-L. Chung, " $1, N^{2}$-Ethenodeoxyguanosine as a potential marker for DNA adduct formation by trans-4hydroxy-2-nonenal," Cancer Research, vol. 48, no. 2, pp. 320323, 1988.

[104] H. Zang, A. K. Goodenough, J.-Y. Choi et al., "DNA adduct bypass polymerization by Sulfolobus solfataricus DNA polymerase Dpo4: analysis and crystal structures of multiple base pair substitution and frameshift products with the adduct $1, N^{2}$-ethenoguanine," Journal of Biological Chemistry, vol. 280, no. 33, pp. 29750-29764, 2005. 

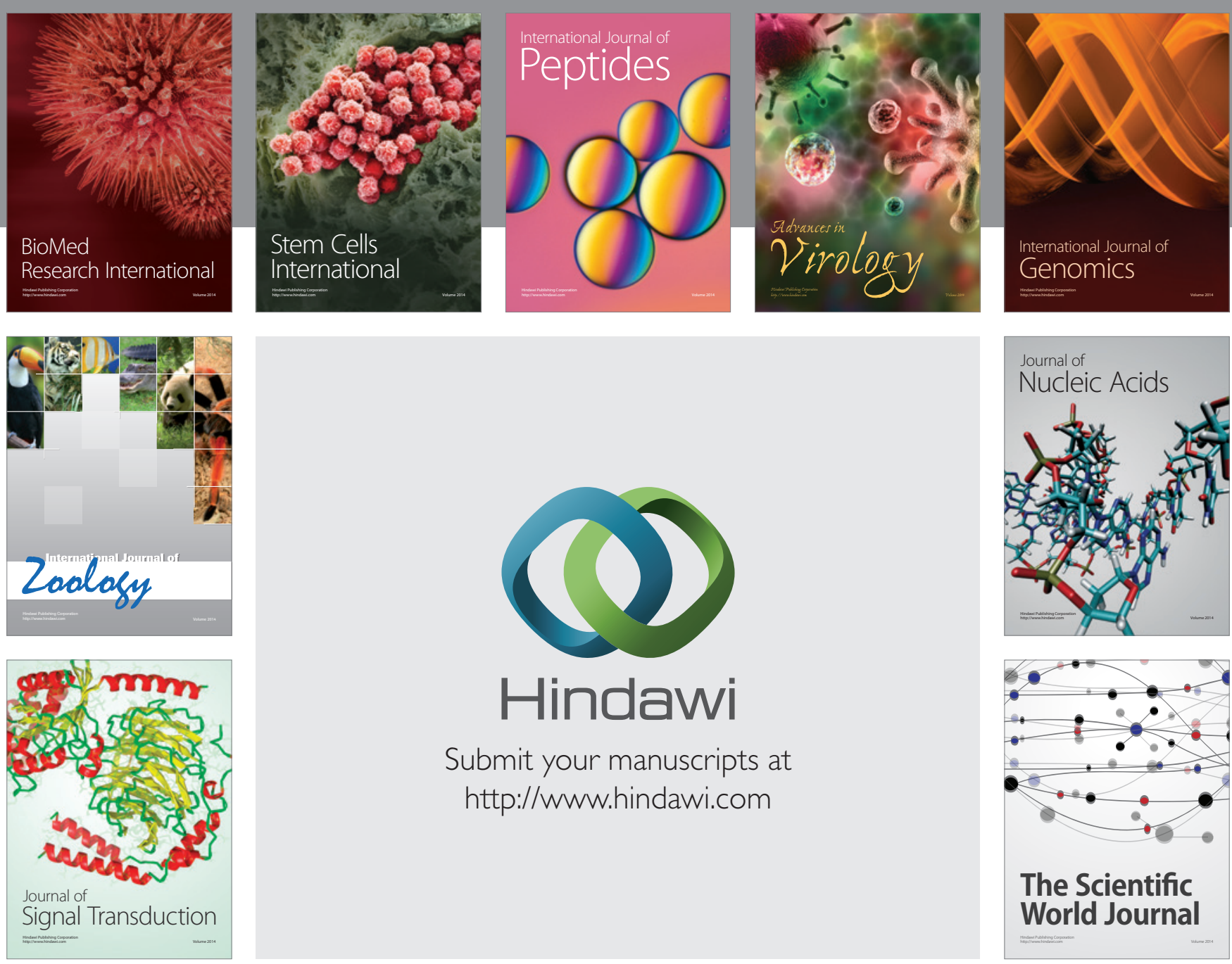

Submit your manuscripts at

http://www.hindawi.com
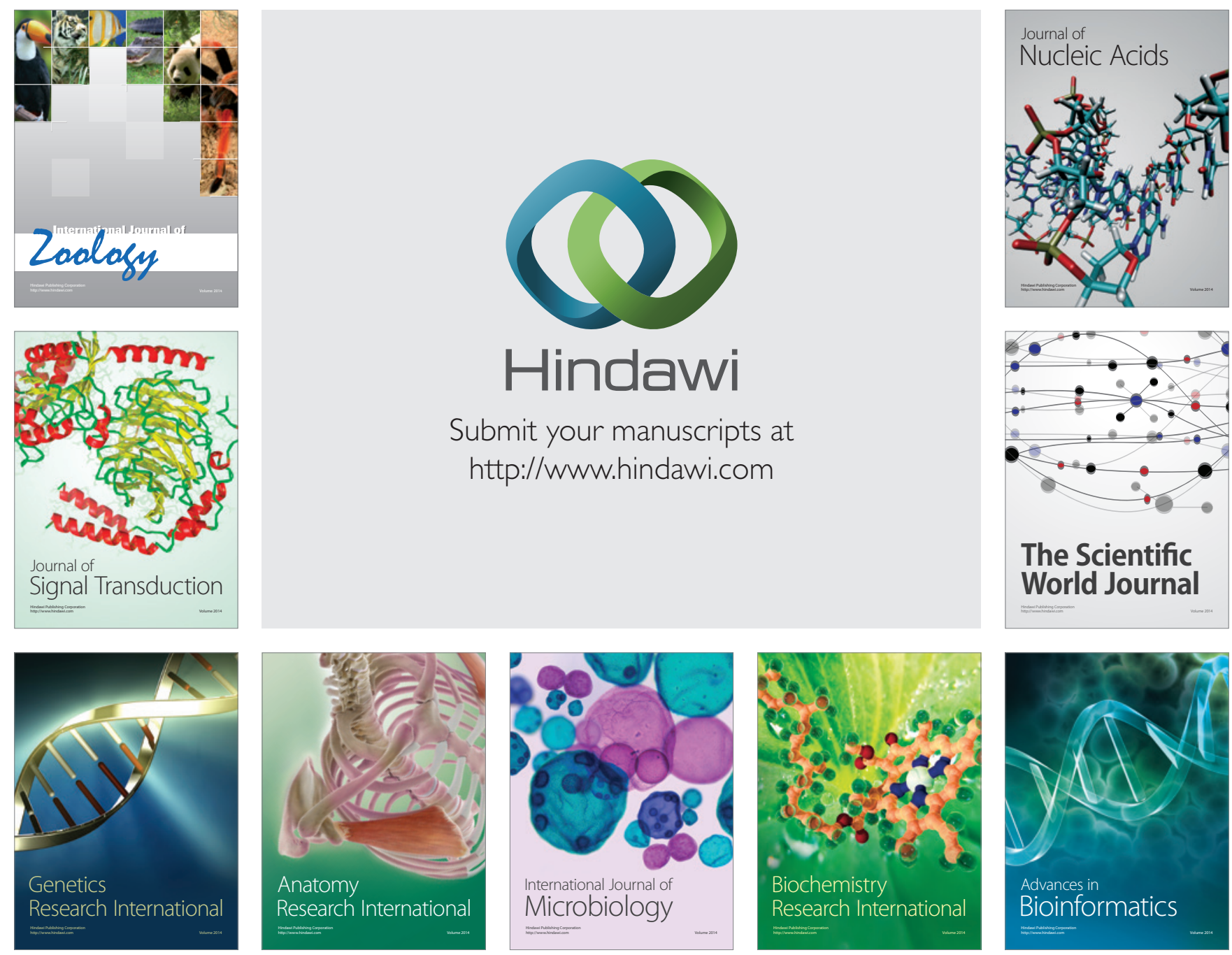

The Scientific World Journal
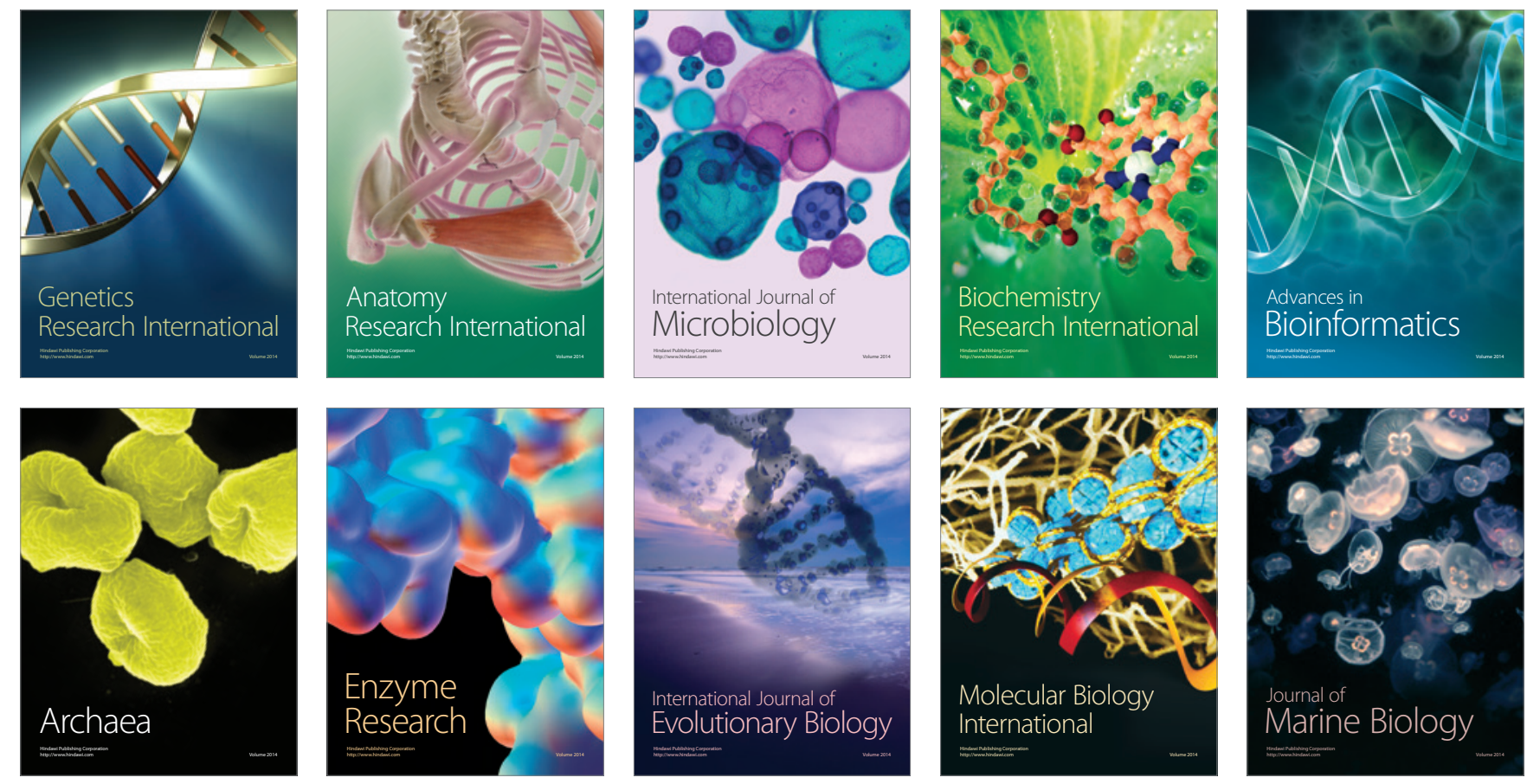